\title{
Nature and Distribution of Stable Subsurface Oxygen in Copper Electrodes During Electrochemical CO2 Reduction
}

Cavalca, Filippo Carlo; Ferragut, Rafael; Aghion, Stefano; Eilert, André; Diaz-Morales, Oscar; Liu, Chang; Koh, Ai Leen; Hansen, Thomas Willum; Pettersson, Lars G.M.; Nilsson, Anders

Published in:

Journal of Physical Chemistry C

Link to article, DOI:

10.1021/acs.jpcc.7b08278

Publication date:

2017

Document Version

Peer reviewed version

Link back to DTU Orbit

Citation (APA):

Cavalca, F. C., Ferragut, R., Aghion, S., Eilert, A., Diaz-Morales, O., Liu, C., Koh, A. L., Hansen, T. W., Pettersson, L. G. M., \& Nilsson, A. (2017). Nature and Distribution of Stable Subsurface Oxygen in Copper Electrodes During Electrochemical CO Reduction. Journal of Physical Chemistry C, 121(45), 25003-25009. https://doi.org/10.1021/acs.jpcc.7b082\%8

\section{General rights}

Copyright and moral rights for the publications made accessible in the public portal are retained by the authors and/or other copyright owners and it is a condition of accessing publications that users recognise and abide by the legal requirements associated with these rights.

- Users may download and print one copy of any publication from the public portal for the purpose of private study or research.

- You may not further distribute the material or use it for any profit-making activity or commercial gain

- You may freely distribute the URL identifying the publication in the public portal 


\section{Nature and Distribution of Stable}

\section{Subsurface Oxygen in Copper Electrodes}

During Electrochemical $\mathrm{CO}_{2}$ Reduction

Filippo Cavalca, ${ }^{1,2}$ Rafael Ferragut, ${ }^{3,4}$ Stefano Aghion, ${ }^{3,4}$ André Eilert, ${ }^{1,2,5}$ Oscar DiazMorales, ${ }^{1}$ Chang Liu, ${ }^{1}$ Ai Leen Koh, ${ }^{6}$ Thomas W. Hansen, ${ }^{7}$ Lars G. M. Pettersson, ${ }^{1}$ and Anders Nilsson ${ }^{*}, 1$

1 Department of Physics, AlbaNova University Center, Stockholm University, S-10691 Stockholm, Sweden

2 SLAC National Accelerator Laboratory, 2575 Sand Hill Road, Menlo Park, California 94025, USA

3 LNESS Laboratory and Dipartimento di Fisica, Politecnico di Milano, Via Anzani 42, 22100 Como, Italy

$4 \quad$ Istituto Nazionale di Fisica Nucleare, via Celoria 16, 20133 Milano, Italy

5 SUNCAT Center for Interface Science and Catalysis, Department of Chemical Engineering, Stanford University, 443 Via Ortega, Stanford, CA 95305, USA

6 Stanford Nano Shared Facilities, Stanford University, 348 Via Pueblo, Stanford, CA 94305, USA

7 Center for Electron Nanoscopy, Technical University of Denmark, Fysikvej 307, 2800

Kgs. Lyngby, Denmark

Corresponding Author 
*Stockholm University, Chemical Physics, 10691 Stockholm, Sweden. Email: andersn@fysik.su.se.

\begin{abstract}
Oxide-derived copper (OD-Cu) electrodes exhibit higher activity than pristine copper during the carbon dioxide reduction reaction $\left(\mathrm{CO}_{2} \mathrm{RR}\right)$ and higher selectivity towards ethylene. The presence of residual subsurface oxygen in OD-Cu has been proposed to be responsible for such improvements, although its stability under the reductive $\mathrm{CO}_{2} \mathrm{RR}$ conditions remains unclear. This work sheds light on the nature and stability of subsurface oxygen. Our spectroscopic results show that oxygen is primarily concentrated in an amorphous 1-2 $\mathrm{nm}$ thick layer within the $\mathrm{Cu}$ subsurface, confirming that subsurface oxygen is stable during $\mathrm{CO}_{2} \mathrm{RR}$ for up to 1 hour at -1.15 V vs RHE. Besides, it is associated with a high density of defects in the OD-Cu structure. We propose that both low-coordination of the amorphous OD-Cu surface and the presence of subsurface oxygen that withdraws charge from the copper sp- and d-bands might selectively enhance the binding energy of $\mathrm{CO}$.
\end{abstract}




\section{Introduction}

The electrochemical carbon dioxide reduction reaction $\left(\mathrm{CO}_{2} \mathrm{RR}\right)$ allows the storage of energy in readily available chemicals such as ethylene and other hydrocarbons, ${ }^{1-3}$ while contributing to the abatement of $\mathrm{CO}_{2}$ emissions and potentially reducing the atmospheric concentration of this greenhouse gas. ${ }^{4,5}$ Copper is the only pure metal able to perform $\mathrm{CO}_{2} \mathrm{RR}$ with appreciable activity and selectivity towards multi-carbon products, due to optimal binding of the key intermediate $\mathrm{CO},{ }^{6,7}$ especially when the electrode is nanostructured and derived from an oxide. ${ }^{8-}$ 16 The improved performance of oxide-derived copper has been correlated with several observations, most notably an increase of local $\mathrm{pH}$ in the pore structure of the nanostructured electrode, ${ }^{17-19}$ an increase of the amount of grain boundaries ${ }^{10,20,21}$ and undercoordinated sites, ${ }^{22}$ or the presence of residual oxides. ${ }^{23-25}$ Recently it was shown that residual subsurface oxygen is observed under the reducing conditions typical of $\mathrm{CO}_{2} \mathrm{RR} \cdot{ }^{26}$ Here, we combine quasi in situ electron energy-loss spectroscopy (EELS) in a scanning transmission electron microscope (STEM), TEM and STEM imaging, and positron annihilation spectroscopy (PAS) to elucidate the nature of subsurface oxygen. Our results and discussion are backed by an accompanying theoretical paper where the stability and effect of subsurface oxygen in model $\mathrm{Cu}$ structures are treated in great detail. ${ }^{27}$

\section{Experimental}

The samples were prepared by drop-casting an Isopropyl Alcohol-based suspension of copper nanoparticles ( $\mathrm{Cu}$ NPs, 20-100 nm in diameter, Sigma-Aldrich $\left.{ }^{\circledR}\right)$ on a copper TEM grid. The samples were subjected to several electrochemical oxidation-reduction cycles (ORC) that were performed in a sealed glove bag purged several times from air and saturated with nitrogen gas. 
The ORCs were performed in an electrolyte consisting of an aqueous solution of $4 \mathrm{mM} \mathrm{KCl}$ (Sigma-Aldrich, TraceSELECT ${ }^{\circledR}$ ) and $0.1 \mathrm{M} \mathrm{KHCO}_{3}$ (Sigma Aldrich, BioUltra ${ }^{\circledR}$ ). The electrolyte was prepared with deionized and ultrafiltrated water from a Millipore System (resistivity $>18.2 \mathrm{M} \Omega \cdot \mathrm{cm}, \mathrm{TOC}<5 \mathrm{ppb}$ ). Prior to the experiments the electrolyte was saturated with $\mathrm{CO}_{2}$ using a glass diffuser and the gas was kept bubbling in the solution during the experiments; the $\mathrm{CO}_{2}$-saturated electrolyte was reported to have a $\mathrm{pH}$ of $6.8 .^{8,9}$

The ORCs for the copper samples were performed in a single-compartment electrochemical cell, by using an $\mathrm{Ag} / \mathrm{AgCl}$ as reference electrode, a boron-doped diamond surface as counter electrode and a $\mathrm{Cu}$ NP-loaded TEM grid as working electrode; the electrochemical experiments were controlled by a Bio-Logic SP-200 potentiostat-galvanostat. All potentials in this work are reported versus the reversible hydrogen electrode (RHE) at $\mathrm{pH}$ 6.8; the applied potentials were converted into the RHE scale according to the equation (1):

$\mathrm{E}_{\mathrm{RHE}}=\mathrm{E}_{\mathrm{Ag} / \mathrm{AgCl} \text { (sat. KCl) }}+\mathrm{E}_{\mathrm{Ag} / \mathrm{AgCl}(\text { sat. KCl) }}^{0}+0.059 \cdot \Delta \mathrm{pH}$

where $E_{R H E}$ is the potential in the RHE scale, $\mathrm{E}_{\mathrm{Ag}} / \mathrm{AgCl}$ (sat. $\mathrm{KCl}$ ) is the potential applied experimentally and $\mathrm{E}_{\mathrm{Ag} / \mathrm{AgCl}(\mathrm{sat} . \mathrm{KCl})}^{0}$ is the standard potential of the $\mathrm{Ag} / \mathrm{AgCl}$ reference electrode in the normal hydrogen electrode scale $(0.197 \mathrm{~V})^{28}$ and $\Delta \mathrm{pH}$ corresponds to the difference between the $\mathrm{pH}$ of the working electrolyte $(\mathrm{pH}$ 6.8) and the conditions used for the normal hydrogen electrode ( $\mathrm{pH} 0)$. 
The working electrode was connected by copper wire and it was immobilized using a polycarbonate tweezer; attention was exercised in order to avoid any other metal than copper in contact with the electrolyte to minimize contamination. The cycling during the ORCs was done at $5 \mathrm{mV} \mathrm{s}^{-1}$ and the potential program was as it follows: during the first cycle, the potential was swept negatively from open circuit potential (OCP) to $-1.15 \mathrm{~V}$, then it was scanned back to 0.1 V. Subsequently, the potential was swept four times between -1.15 and $0.1 \mathrm{~V}$ and then three times between -1.15 and $0.7 \mathrm{~V}$. The potential cycling was finally interrupted at $-1.15 \mathrm{~V}$ and the samples were held at $-1.15 \mathrm{~V}$ for 55 minutes (see Figure S1 for details of the ORCs). After the potential program, while holding the potential and inside the protective nitrogen atmosphere, the sample was pulled out of the electrolyte, thoroughly washed in Millipore water, dried with pure nitrogen gas, inserted into a Fischione Model 2560 vacuum transfer holder, sealed inside it and transferred to the transmission electron microscope (TEM), so that it was never exposed to air. The sample was extracted from the transfer holder only when a pressure inside the microscope column reached $c a \cdot 1 \cdot 10^{-6} \mathrm{hPa}$.

TEM was performed using two different aberration-corrected FEI Titan 80-300 microscopes. A microscope equipped with an aberration corrector for the image-forming optics was used for high resolution TEM (HRTEM) imaging (at the Stanford Nano Shared Facilities), whereas one equipped with a corrector for the probe-forming optics was used for scanning TEM (STEM) annular dark field (ADF) imaging and STEM electron energy-loss spectroscopy (EELS) (at the Center for Electron Nanoscopy, Technical University of Denmark), respectively. Both microscopes were operated at a primary electron energy of $300 \mathrm{keV}$, at the base vacuum of ca. $1 \cdot 10^{-6} \mathrm{hPa}$. For the acquisition of EELS in STEM mode a convergence semi-angle of $17.6 \mathrm{mrad}$ and a collection semi-angle of $8.3 \mathrm{mrad}$, an energy dispersion of $0.5 \mathrm{eV} / \mathrm{channel}$, and an 
exposure time of 5 seconds per spectrum were used. The exposure time was chosen so that no visible sample damage could be detected in the ADF images acquired after each EELS scan. Spectra were processed using DigitalMicrograph and the EELS energy scale was calibrated using the zero-loss peak as a reference. Background subtraction was performed by extrapolation of a power law fitted to the spectra in the energy range preceding the $\mathrm{O}$ K-edge. Spectral quantification was performed using integral methods. ${ }^{29} \mathrm{~A}$ fresh sample was prepared for analysis in each of the two microscopes.

After the experiment, the TEM grid was extracted from the microscope and examined in a scanning electron microscope (SEM) to investigate surface morphology. During the transfer the sample was exposed to air.

Online electrochemical mass spectrometry (OLEMS) was performed on a sample prepared in identical fashion, in order to compare catalytic activity and selectivity of the pristine and modified specimen. ${ }^{9,19}$ The details of the OLEMS setup used are described in literature. ${ }^{30}$

Positron annihilation spectroscopy (PAS) was performed on a separate set of polycrystalline copper foil samples. The samples were prepared in a protective nitrogen atmosphere within a glove bag, following the same procedure described for the TEM sample preparation. After the ORCs, the samples were sealed and transferred to the VEPAS laboratory (LNESS Center at the Politecnico di Milano). The samples were introduced into the vacuum chamber using a sealed glove bag purged several times from air and saturated with nitrogen gas.

Positron annihilation spectroscopy was used to monitor the defects associated to the subsurface of the OD-Cu sample. In order to obtain depth-resolved annihilation data, positrons were implanted in the sample at various depths using a variable-energy positron beam (from 0.1 to 17 $\mathrm{keV}$ ). Two ultrapure Ge gamma detectors (Ortec, relative efficiency $\sim 50 \%$ at $1.33 \mathrm{MeV}$ ) were 
used to measure the spectrum of the annihilation radiation. The PAS measurements were performed at room temperature at a vacuum level of $\sim 10^{-7}$ to $\sim 10^{-8} \mathrm{hPa}$. The reader should refer to the Supplementary Information for a detailed description of the PAS experimental procedure and data analysis.

The annihilation peak $(511 \mathrm{keV})$ is broadened by the Doppler effect due to the motion of the electrons annihilating with positrons. ${ }^{31}$ For characterization purposes, it is convenient to divide the annihilation peak in two energy regions and associate their respective area to parameters. The first, called Shape- or $S$-parameter, is associated to the fraction of annihilating positron-electron pairs with momenta $\left|p_{L}\right| \leq 0.456$ atomic units, corresponding to the energy range within $511 \pm 0.85 \mathrm{keV}$. The second, called $W$ ing- or $W$-parameter (also known as the core-annihilation parameter), corresponds to the high-momentum region far from the center part of the peak, within the energy range from $511 \pm 1.8 \mathrm{keV}$ to $511 \pm 4 \mathrm{keV}$. Finally, the total area of the annihilation peak is taken in the energy range $511 \pm 4.25 \mathrm{keV}$. The $\mathrm{S}$-parameter corresponds to annihilation of positrons with valence electrons in the sample (and para-positronium, see section $\mathrm{S} 4.4$ in SI). The W-parameter, i.e. the signal in the tails of the annihilation peak corresponding to a high Doppler shift, is associated to annihilation with the core electrons in the sample. The low count-rate in the high momentum region requires background suppression, which is obtained by adopting the coincidence Doppler broadening technique (CDB). CDB spectra with $\sim 10^{7}$ total counts were measured with a peak/background ratio of $10^{5}$ to $10^{6}$. The momentum resolution (FWHM) was $3.5 \times 10^{-3} m_{0} c$. The experimental procedure used in this study can be found in literature. $^{32}$ 


\section{Results and discussion}

Quasi in situ STEM investigation was performed during the electrochemical production of oxide-derived $\mathrm{Cu}(\mathrm{OD}-\mathrm{Cu})$. In particular, the copper sample was analyzed in the oxidized state subsequently in the reduced OD-Cu state, without exposing the sample to air during transfer from the electrochemical cell to the microscope (see Experimental section). A representative STEM- annular dark field (ADF) image of oxidized Cu nanoparticles (NPs, Figure 1a) shows that the NPs have cubic shape with irregular widths ranging between 20 and $100 \mathrm{~nm}$. In the OD$\mathrm{Cu}$ sample ( Figure $1 \mathrm{~b}$ and $\mathrm{S} 3$ ), the cubic shape is not observed in the reduced sample. The effect of electrochemical oxidation and reduction of the TEM sample was verified by online electrochemical mass spectrometry (OLEMS) ( Figure 1c), showing suppressed methane and enhanced ethylene production with the OD-Cu sample. This indicates that the oxidationreduction cycles (ORCs, see SI) influence chemical activity and selectivity as well as the structure of the specimen, consistent with results reported by Roberts et al. ${ }^{19}$ The sample composition was determined by EELS ( Figure 1d). For the oxidized sample (black curve in Figure 1d), a relative composition of $\sim 66$ at. $\% \mathrm{Cu}$ and $\sim 34$ at. $\% \mathrm{O}$ was measured as spatial average over entire particles, matching the stoichiometric composition of cuprous oxide $\left(\mathrm{Cu}_{2} \mathrm{O}\right)$, whereas for the reduced sample a relative average composition of $\sim 95$ at. $\% \mathrm{Cu}$ and $\sim 5$ at. $\% \mathrm{O}$ was obtained. It should be noted that the average composition is acquired in transmission through entire particles, thus this measurement is not surface-sensitive. The average composition indicates that the reduced sample still contains oxygen after the electrochemical treatment, in agreement with previous in situ XPS investigations. ${ }^{26}$ Residual oxygen cannot arise from the atmosphere, as the samples were always kept in an oxygen-free environment. Besides, the 
Millipore water used for rinsing cannot oxidize copper either. In fact, subsurface oxygen has been resolved by is situ XPS in a similar experiment that did not involve a rinsing phase. ${ }^{26}$
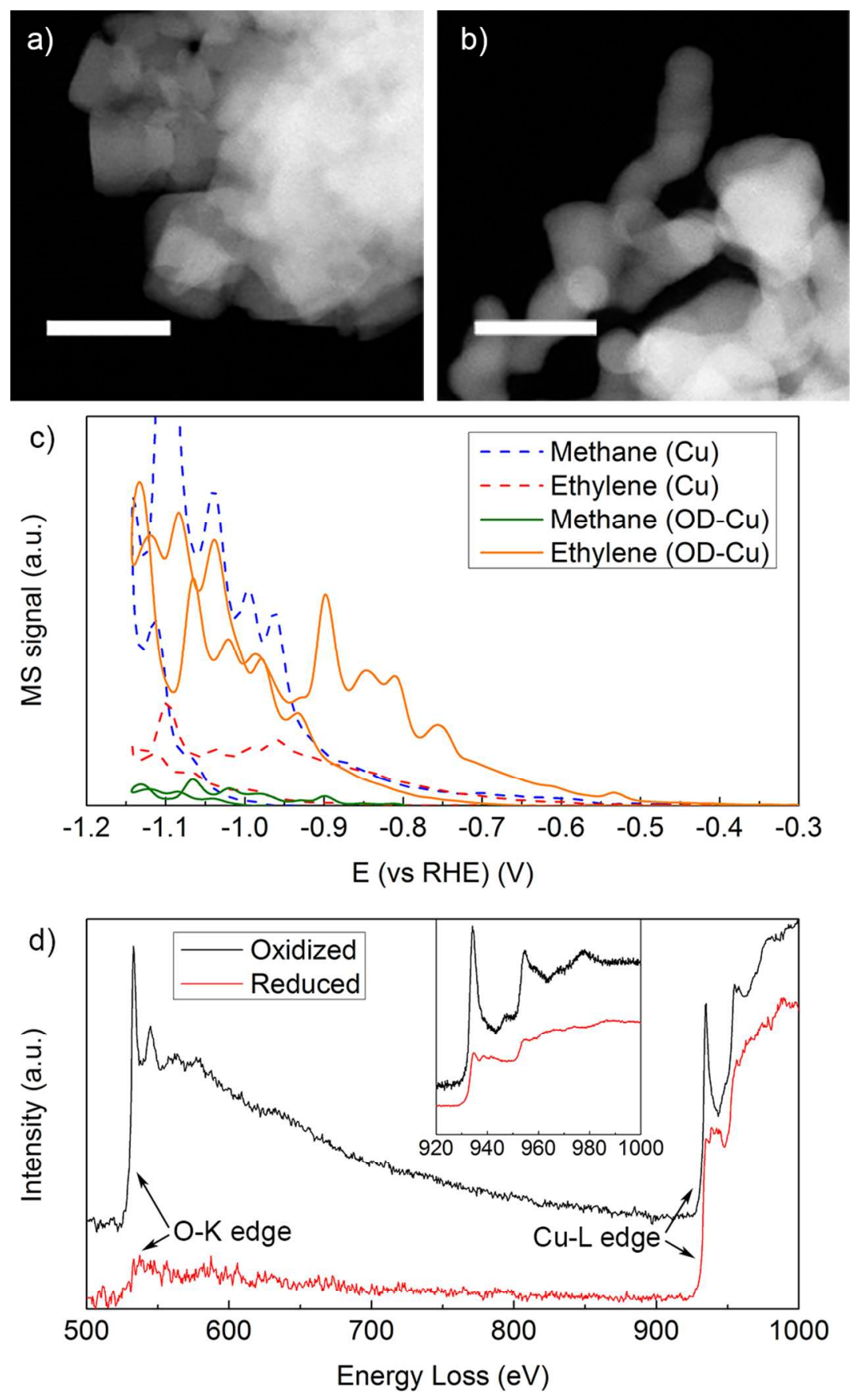

Figure 1. In situ STEM ADF images of Cu nanoparticles (a) in the oxdidized phase and (b) in the reduced oxide-derived state. Scale bars are $100 \mathrm{~nm}$. (c) Online electrochemical mass 
spectrometry (OLEMS) data of the sample before (solid lines) and after (dashed lines) electrochemical treatment. (d) EEL spectra of entire particles of the oxidized (a) and reduced (b) sample.

High-resolution TEM images of OD-Cu NPs after ORC (Figure 2a and S4) reveal the presence of a 1-2 nm thick amorphous layer within the particle subsurface, whereas the $\mathrm{Cu}(111),(200)$ and (220) lattice spacing $(\sim 2.08, \sim 1.80$, and $\sim 1.27 \AA$, respectively) are well resolved in the bulk of the particle (Figure 2a-b, S4). Notably, no spacing associated to $\mathrm{Cu}_{2} \mathrm{O}$ or $\mathrm{CuO}$ are resolved in the OD-Cu sample, while the $\mathrm{Cu}_{2} \mathrm{O}$ (111) and (200) lattice fringes $(\sim 2.46$ and $\sim 2.13 \AA$, respectively) are visible in the as-received $\mathrm{Cu}$ nanoparticles (Fig. S5), forming a native oxide layer up to $\sim 10 \mathrm{~nm}$ thick. STEM-EELS (Figure 2c, S7 and S8) reveals that the amorphous layer contains copper and oxygen with a relative average composition of $\sim 80$ at. $\%$ and $\sim 20$ at. $\%$, respectively (Figure 2d, S7 and S8), and does not contain carbon (Fig. S6). It should be noted that this measurement is spatially-resolved, aimed at the subsurface region, and thus subsurfacesensitive. Both the average thickness of the amorphous layer and its average oxygen concentration remain unchanged immediately after reduction and after $1 \mathrm{~h}$ prolonged potential hold at $-1.15 \mathrm{~V}$ vs RHE. However, the oxygen-rich layer exhibits a variable thickness across the sample, ranging from $\sim 0.5$ to $\sim 3 \mathrm{~nm}$, and the local oxygen concentration varies from $\sim 5$ to $\sim 30$ at. \%. There is no correlation between the crystallographic orientation of the support particles, amorphous layer thickness and local oxygen concentration. The stability of the amorphous oxygen-rich layer under reducing conditions is thought to be possible due to the high local $\mathrm{pH}$ found in proximity of the catalyst surface during $\mathrm{CO}_{2} \mathrm{RR}^{23-25}$ The effect of the local $\mathrm{pH}$ during 
$\mathrm{CO}_{2} \mathrm{RR}$ is particularly marked in $0.1 \mathrm{M} \mathrm{KHCO}_{3}$ where the buffer capacity of the electrolyte is exhausted during the reaction, and $\mathrm{SI}^{33}$
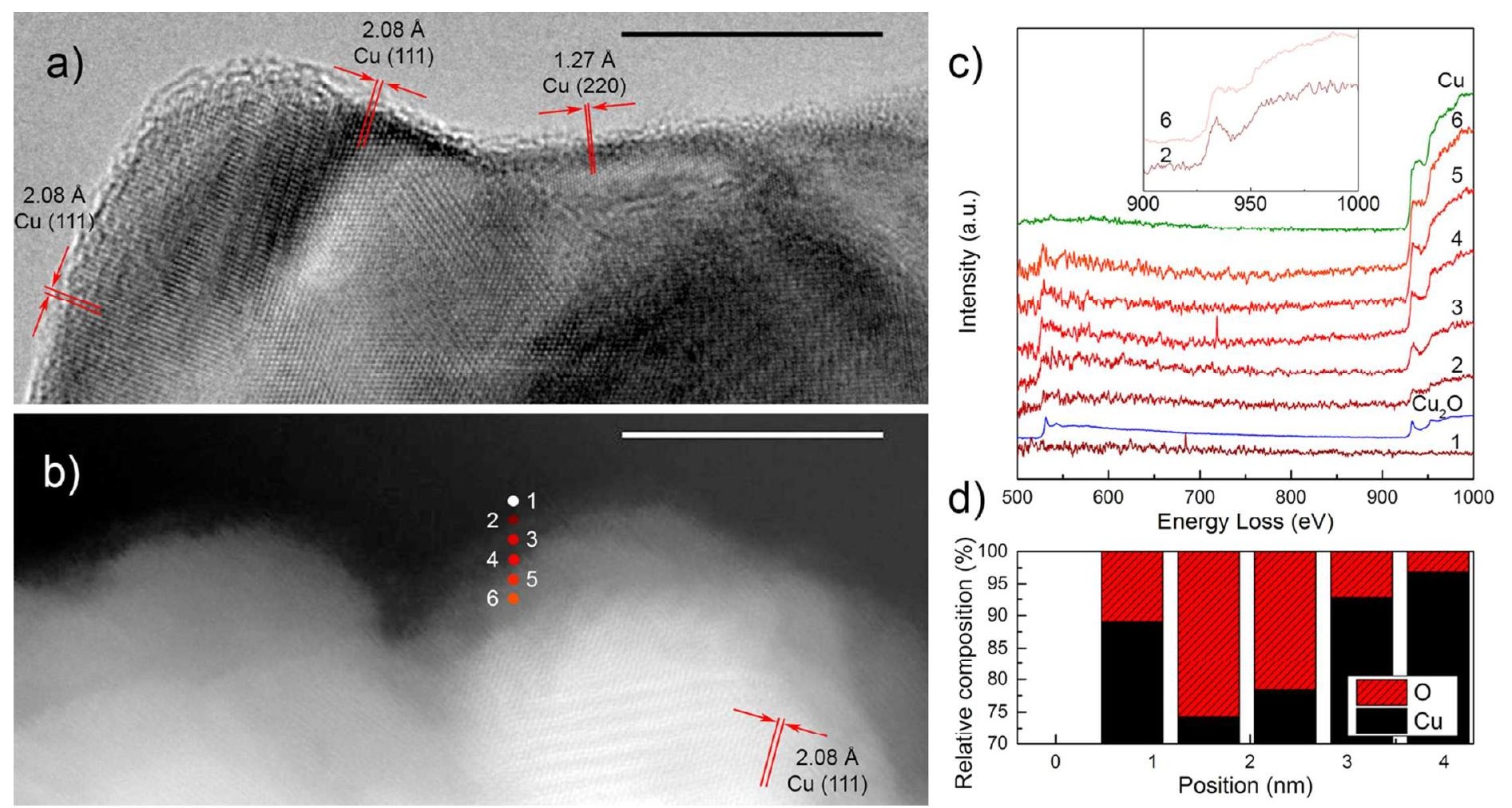

Figure 2. (a) HRTEM and (b) STEM ADF image of different OD-Cu nanoparticles (after ORC).

Scale bars are $10 \mathrm{~nm}$. (c) STEM EEL spectra acquired at the points indicated in (b). Reference spectra for $\mathrm{Cu}_{2} \mathrm{O}$ and $\mathrm{Cu}$ are shown in blue and green, respectively. In the inset, the $\mathrm{Cu} \mathrm{L}_{3,2}$ edge regions of spectra 2 and 6 are displayed for comparison. (d) Quantitative analysis of the STEM EEL spectra reporting the relative composition of the catalyst as a function of depth from the surface.

Furthermore, the presence of residual oxygen after electrochemical reduction is associated with a change in the $\mathrm{Cu} \mathrm{L}_{3}$ edge intensity (Figure 2c, S7 and S8). The $\mathrm{Cu} \mathrm{L}_{3}$ edge exhibits a peak-like shape within the first 1-2 $\mathrm{nm}$ from the surface, where the amorphous oxygen-rich layer is found, whereas the $\mathrm{Cu} \mathrm{L}_{3}$ edge is characterized by a smoother edge-like shape in the bulk of the particle. 
Since the EELS $\mathrm{L}_{3}$ edge of transition metals corresponds to electronic transitions from the $\mathrm{p}$ to the $\mathrm{d}$ electronic states, the energy-loss near edge structure (ELNES) of the copper $\mathrm{L}_{3}$ edge is strongly related to the metal d-band occupancy. ${ }^{34-38}$ The $\mathrm{Cu}$ d-band is full in metallic copper $\left(\mathrm{Cu}^{0}\right)$, whereas it is partly depleted in copper oxides $\left(\mathrm{Cu}^{+}\right.$and $\left.\mathrm{Cu}^{2+}\right)$. Since $\mathrm{p} \rightarrow \mathrm{d}$ transitions are enhanced by the presence of unoccupied states in the d-band, a high $\mathrm{Cu}_{3}$ edge ELNES intensity is expected in copper oxides. ${ }^{35,37}$ In the spectra shown in Figure $2 \mathrm{c}$, the $\mathrm{L}_{3}$ edge is not fully comparable to that of $\mathrm{Cu}_{2} \mathrm{O}$, but the more oxide-like edge shape near the particle surface suggests that the residual oxygen interacts with copper and withdraws charge from the $\mathrm{Cu}$ d-orbitals. The interplay between $\pi$ bonding and $\sigma$ repulsion governs the bonding between $\mathrm{Cu}$ substrate and adsorbates. $^{26,39-42}$ DFT calculations show that the observed withdrawal of electronic density away from $\mathrm{Cu}$ surface atoms enhances the adsorption strength of $\mathrm{CO}$ on $\mathrm{Cu}(100)$ by reduction of the $\sigma$-repulsion. Owing to this effect, the coverage of CO may be increased, resulting in a higher probability of OC-CO dimerization and thereby promoting multi-C product formation. ${ }^{27}$

Positron annihilation spectroscopy (PAS) was performed on polycrystalline $\mathrm{Cu}$ foils that underwent the same electrochemical treatment as the TEM sample. Figure 3a shows the evolution of the S-parameter measured for the as-received (polycrystalline $\mathrm{Cu}$ foil), oxidized, and reduced $(\mathrm{OD}-\mathrm{Cu})$ samples as a function of the positron implantation energy (see section S4.1 in SI). The S-parameter is mainly correlated with the annihilation of the valence electrons of the material, its values are associated to the chemical environment surrounding annihilation sites and tend to increase with the density of defects. Since positron implantation energy is correlated with the depth of penetration of positrons (Fig. S9), a plot of S as a function of implantation energy (Figure 3a) represents a depth profile of composition and defect concentration. 
For the oxidized sample, at energies below 7-8 keV the S-parameter remains approximately constant at a value $\approx 0.515$, associated with annihilation in $\mathrm{Cu}_{2} \mathrm{O}$ (see section $\mathrm{S} 4.2$ in $\mathrm{SI}$ ), while a rapid decrease of the S-value is observed at energies above $8 \mathrm{keV}$. On the other hand, the Sparameter for the as-received sample decreases smoothly with increasing implantation energy, starting from a low-energy value of $\approx 0.52$. This suggests that the outer layer of the as-received sample has a chemical environment similar to $\mathrm{Cu}_{2} \mathrm{O}$ and is also influenced by positronium formation (Fig. S10). In fact, a $\mathrm{Cu}_{2} \mathrm{O}$ native layer of about $2 \mathrm{~nm}$ is expected at the surface of the as-received sample (Fig. S5). At high implantation energies, the S-parameter curve of the asreceived sample tends to an asymptotic value of 0.48 (black circle in Figure 3a), which in our case is the S-parameter value of the bulk copper. The S-parameter of the oxidized sample does not reach the same plateau because a fraction of positrons still annihilates within the NP layer (Fig. 3b), characterized by a higher S-parameter value.

The S-parameter values of OD-Cu are lower than the values of the oxidized sample (blue and red arrows in Figure 3, respectively). Since low and high S values are typical of metallic and oxidic $\mathrm{Cu}$, respectively, this indicates that the chemical environment near annihilation sites in the OD- $\mathrm{Cu}$ sample has more metallic character than $\mathrm{Cu}_{2} \mathrm{O}$. Finally, for the OD-Cu and oxidized samples the S-curve starts decreasing at $\sim 5$ and $\sim 7-8 \mathrm{keV}$, respectively. This difference might be due to the lower average thickness of the NPs film in OD-Cu with respect to that in the oxidized sample. 


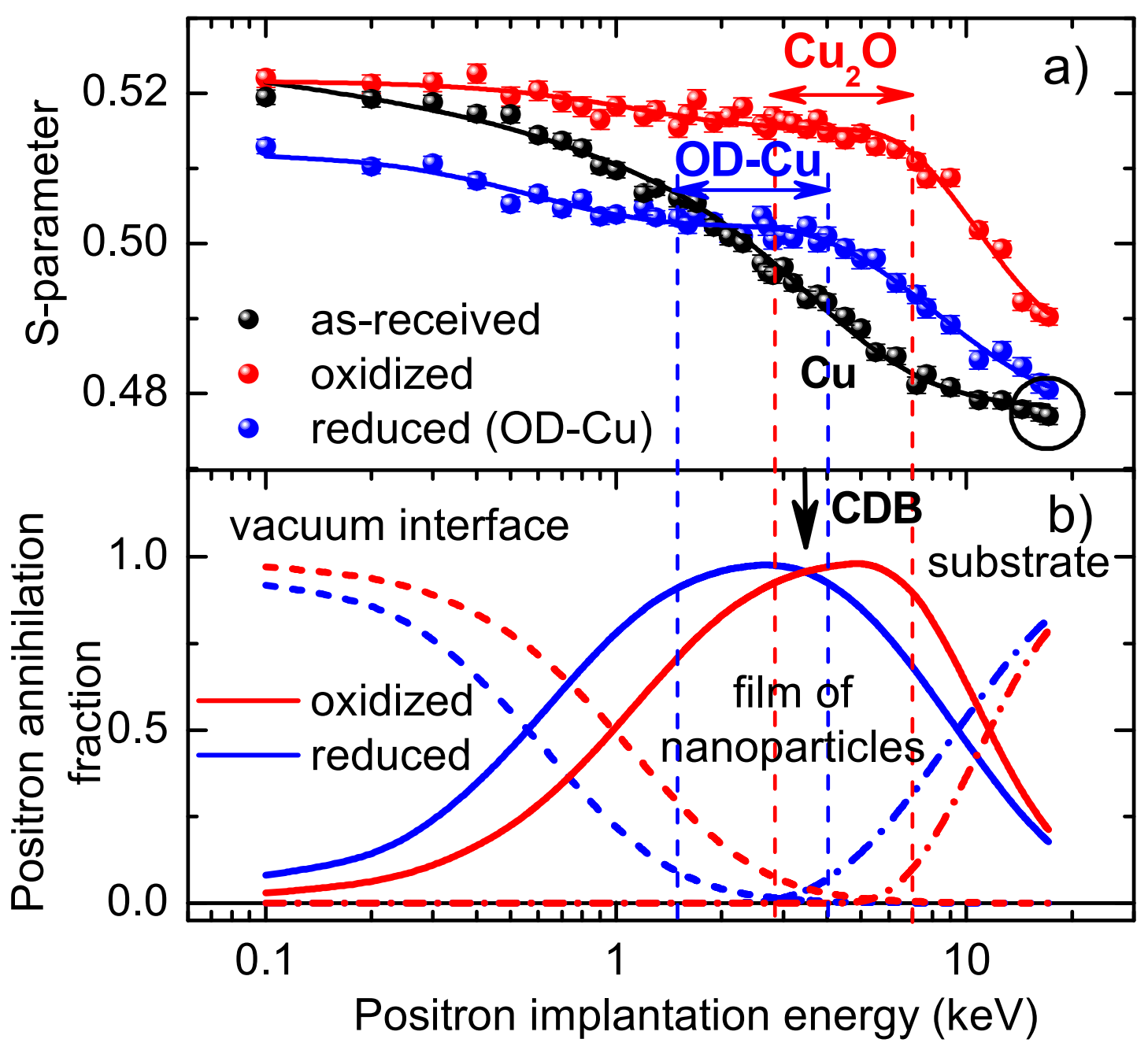

Figure 3. Annihilation parameters as a function of the positron implantation energy. (a) $S$ parameter values measured for the as-received (black), oxidized (red) and reduced OD-Cu (blue) samples. The continuous lines represent the best fits to the data (see sections S4.3 and S4.7 in SI). (b) positron annihilation fraction for oxidized (red) and reduced (blue) samples. Dashed, solid and dash-dotted lines correspond to the vacuum interface, the film that contains the nanoparticles and the $\mathrm{Cu}$ substrate, respectively. The black arrow indicates the positron energy chosen for CBD measurements. 
To obtain more detailed chemical information on the films of NPs, coincidence Doppler broadening (CDB) spectra of the oxidized and OD-Cu samples were acquired at a fixed implantation energy of $3.5 \mathrm{keV}$. The CDB distribution is sensitive to the average chemical composition surrounding the annihilation sites. ${ }^{32,43}$ An energy of $3.5 \mathrm{keV}$ was chosen because at such energy $\sim 97 \%$ of the positrons annihilate within the nanoparticle film in both oxidized and OD-Cu samples (black arrow in Figure 3). Furthermore, based on diffusion considerations (see section S4.2 in SI), in the OD-Cu sample the majority of such positrons annihilates in the NPs subsurface. Figure $4 \mathrm{a}$ shows the momentum distribution $\rho\left(p_{L}\right)$ of the oxidized and OD-Cu samples, as well as of an annealed, high-purity (99.99\%) $\mathrm{Cu}$ reference sample. ${ }^{32}$ EELS results indicate that the oxidized sample is an excellent reference for $\mathrm{Cu}_{2} \mathrm{O}\left(\rho_{\mathrm{Cu}_{2} \mathrm{O}}\right)$. Figure $4 \mathrm{~b}$ shows the relative difference of the momentum distribution $\Gamma_{O D r}$ between the reduced OD-Cu and oxidized $\mathrm{Cu}$, defined as:

$$
\Gamma_{O D r}=\left(\rho_{O D-C u}-\rho_{C u_{2} O}\right) / \rho_{C u_{2} O}
$$

where $\rho_{\mathrm{Cu}_{2} \mathrm{O}}$ and $\rho_{\mathrm{OD}-\mathrm{Cu}}$ are the momentum distributions of $\mathrm{Cu}_{2} \mathrm{O}$ and $\mathrm{OD}-\mathrm{Cu}$, respectively. The momentum distribution of $\mathrm{OD}-\mathrm{Cu}$ is qualitatively similar to that of $\mathrm{Cu}_{2} \mathrm{O}$ (Figure 4a). However, $\Gamma_{O D r}$ shows that $\rho_{O D-C u}$ is higher around \pm 2 atomic units (Figure $4 \mathrm{~b}$ ). The momentum region and the form of such signal is attributed to the $3 \mathrm{~d}$ electrons of metallic $\mathrm{Cu}{ }^{32}$ indicating that the chemical environment surrounding defects in OD-Cu is richer in $\mathrm{Cu}$ than in the oxidized sample, consistent with the observed reduction from $\mathrm{Cu}_{2} \mathrm{O}$. The subsurface of the OD-Cu NPs is defectrich, i.e. it contains low-coordination sites, vacancies, and voids that act as positron traps. ${ }^{22}$ It was not possible to obtain a good fit of $\rho_{O D-C u}$ using a linear combination of the two terms $\rho_{C u_{2} O}$ and $\rho_{C u}$ alone (see section S4.7 in SI). ${ }^{32,43}$ An additional minority term presented in Fig. $4 \mathrm{c}$ as a ratio 
relative to $\mathrm{Cu}\left(\rho / \rho_{\mathrm{Cu}}\right)$ with similar characteristics to cupric oxide $(\mathrm{CuO})^{44}$ was necessary to accurately fit the $\rho_{O D-C u}$ spectrum. The resulting spectral contributions of $\mathrm{Cu}, \mathrm{Cu}_{2} \mathrm{O}$ and $\mathrm{CuO}$ are 18,70 , and $12 \%$, respectively (see Fig. S12).

This indicates that the defects, i.e. vacancies and/or small voids, are mainly associated to residual oxygen in the catalyst, and that the atomic concentration of oxygen around such defects is in the order of $\mathrm{Cu}: \mathrm{O} \approx 2: 1$, although the average oxygen concentration in the amorphous layer is close to $\mathrm{Cu}: \mathrm{O} \approx 4: 1$, as shown by EELS. Therefore, the local oxidation state of copper in proximity of defects can be higher than the average subsurface region, which was probed using STEM-EELS. $\mathrm{Cu}$ might have a higher oxidation state around defects to stabilize oxygen but $<1$ on the surface where catalysis takes place. 


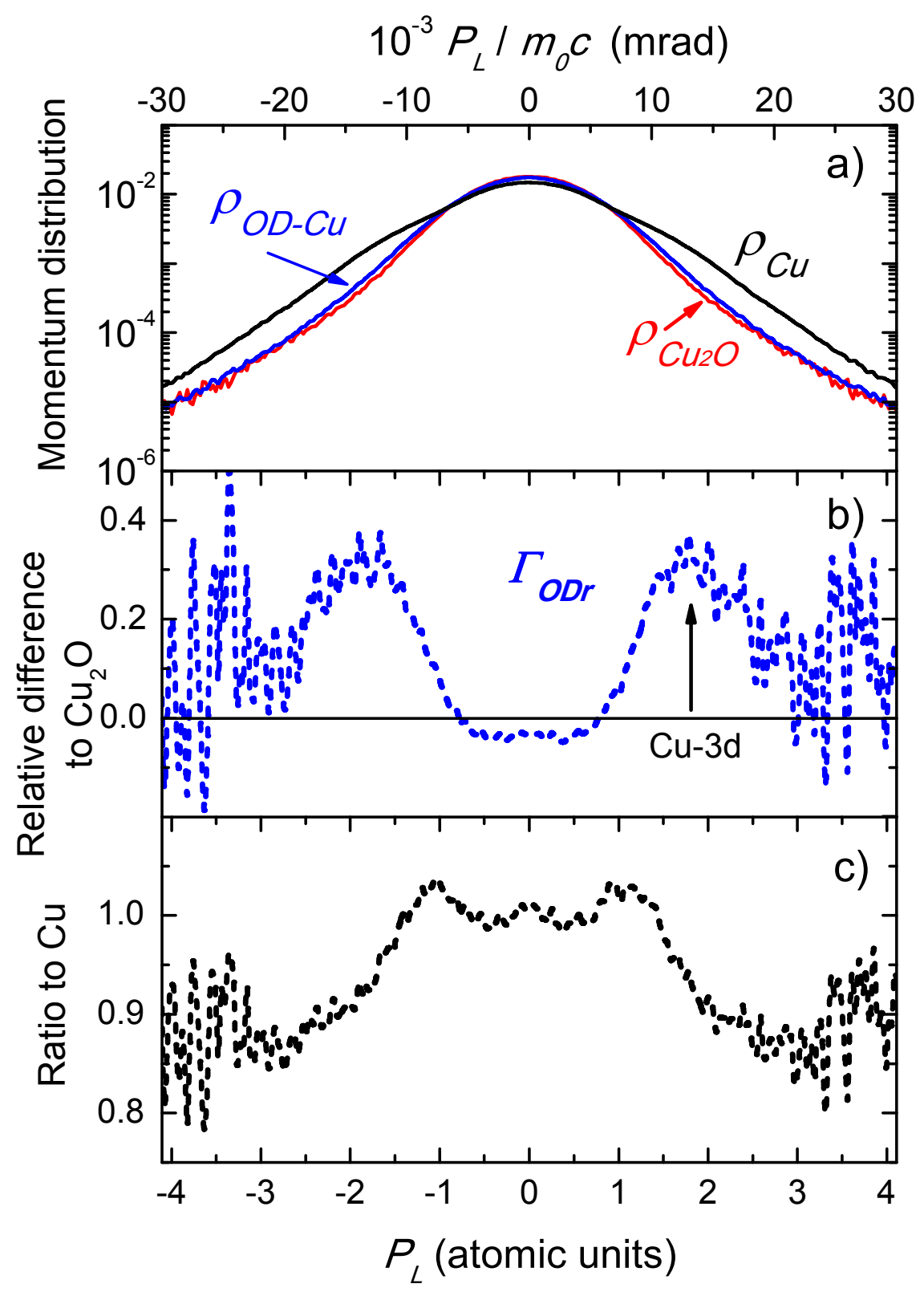

Figure 4. a) $C D B$ momentum distribution of the oxidized (red) and reduced OD-Cu (blue) samples, obtained with a positron implantation energy of $3.5 \mathrm{keV}$. The CDB spectrum of a highpurity $\mathrm{Cu}$ reference with a low defect concentration (black) is also shown. b) Relative difference of the momentum distribution of reduced OD-Cu with respect to that of the oxidized sample. c) Ratio curve of the residual fitting term relative to $\mathrm{Cu}$, with characteristics similar to $\mathrm{CuO}{ }^{44}$ 


\section{Conclusions}

Using a combination of quasi in situ TEM and PAS, we were able to investigate the nature of OD- $\mathrm{Cu}$ electrodes during $\mathrm{CO}_{2} \mathrm{RR}$. Oxygen is present in an amorphous 1-2 $\mathrm{nm}$ thick copper layer on the OD-Cu electrode surface. The oxygen content and distribution did not change after holding the potential at $-1.15 \mathrm{~V}$ vs RHE for $1 \mathrm{~h}$, indicating that subsurface oxygen is stable for an extended time under such conditions. The observation of an amorphous layer is in agreement with the increase in superficial defect concentration measured by PAS. The chemical environment surrounding defects is oxygen-rich, indicating that oxygen in the subsurface region is stabilized by defects such as vacancies and voids. Finally, EELS analysis of the $\mathrm{Cu}_{3}$ edge within the top 1-2 $\mathrm{nm}$ from the particle surface shows that copper is in a partly oxidized state, in agreement with the PAS CDB observation of a partly oxidic copper character in proximity of defects. We conclude that the combination of low-coordination subsurface sites and the presence of residual subsurface oxygen depleting the $\mathrm{Cu}$ sp- and d-bands are responsible for the enhanced $\mathrm{CO}$ adsorption energy in $\mathrm{OD}-\mathrm{Cu}$, which results in increased activity and selectivity towards multi-carbon products. We propose that the defect- and oxygen-rich nature of the catalyst subsurface changes the electronic properties of the catalyst during $\mathrm{CO}_{2} \mathrm{RR}$. In particular, lowcoordination adsorption sites, known to be present on amorphous surfaces, might provide optimal distance between reaction intermediates for C-C coupling. ${ }^{45,46}$

\section{Supplementary Information Available}

Electrochemistry. Scanning electron microscopy. Transmission electron microscopy. Positron annihilation spectroscopy. 


\section{Acknowledgements}

Financial support for this work was provided by the Knut and Alice Wallenberg (KAW) Foundation and the Swedish Energimyndigheten. Scanning Electron Microscopy (SEM) was performed at the Electron Microscopy Center (EMC) at Stockholm University. The authors acknowledge Kjell Jansson for the assistance, and E. A. Fischione Instruments Inc. for their generous loan of the vacuum transfer TEM specimen holder. Transmission Electron Microscopy (TEM) was performed at the Stanford Nano Shared Facilities (SNSF) and at the Technical University of Denmark, Center for Electron Nanoscopy (DTU CEN). CPU time was provided by the Swedish National Infrastructure for Computing (SNIC) at the HP2CN center.

\section{References}

(1) Hori, Y. Electrochemical $\mathrm{CO}_{2}$ Reduction on Metal Electrodes. In Modern Aspects of Electrochemistry; Springer, 2008; pp 89-189.

(2) Kuhl, K. P.; Cave, E. R.; Abram, D. N.; Jaramillo, T. F. New Insights into the Electrochemical Reduction of Carbon Dioxide on Metallic Copper Surfaces. Energy Environ. Sci. 2012, 5, 7050.

(3) Kuhl, K. P.; Hatsukade, T.; Cave, E. R.; Abram, D. N.; Kibsgaard, J.; Jaramillo, T. F. Electrocatalytic Conversion of Carbon Dioxide to Methane and Methanol on Transition Metal Surfaces. J. Am. Chem. Soc. 2014, 136, 14107-14113.

(4) Lewis, N. S.; Nocera, D. G. Powering the Planet: Chemical Challenges in Solar Energy Utilization. Proc. Natl. Acad. Sci. 2006, 103, 15729-15735.

(5) Gattrell, M.; Gupta, N.; Co, A. Electrochemical Reduction of $\mathrm{CO}_{2}$ to Hydrocarbons to Store Renewable Electrical Energy and Upgrade Biogas. Energy Convers. Manag. 2007, 
$48,1255-1265$.

(6) Peterson, A. A.; Nørskov, J. K. Activity Descriptors for $\mathrm{CO}_{2}$ Electroreduction to Methane on Transition-Metal Catalysts. J. Phys. Chem. Lett. 2012, 3, 251-258.

(7) Ma, X.; Li, Z.; Achenie, L. E. K.; Xin, H. Machine-Learning-Augmented Chemisorption Model for $\mathrm{CO}_{2}$ Electroreduction Catalyst Screening. J. Phys. Chem. Lett. 2015, 6, 35283533.

(8) Roberts, F. S.; Kuhl, K. P.; Nilsson, A. High Selectivity for Ethylene from Carbon Dioxide Reduction over Copper Nanocube Electrocatalysts. Angew. Chemie 2015, 127, $5268-5271$.

(9) Eilert, A.; Roberts, F. S.; Friebel, D.; Nilsson, A. Formation of Copper Catalysts for $\mathrm{CO}_{2}$ Reduction with High Ethylene/Methane Product Ratio Investigated with In Situ X-Ray Absorption Spectroscopy. J. Phys. Chem. Lett. 2016, 1466-1470.

(10) Li, C. W.; Ciston, J.; Kanan, M. W. Electroreduction of Carbon Monoxide to Liquid Fuel on Oxide-Derived Nanocrystalline Copper. Nature 2014, 508, 504-507.

(11) Ren, D.; Deng, Y.; Handoko, A. D.; Chen, C. S.; Malkhandi, S.; Yeo, B. S. Selective Electrochemical Reduction of Carbon Dioxide to Ethylene and Ethanol on Copper(I) Oxide Catalysts. ACS Catal. 2015, 5, 2814-2821.

(12) Raciti, D.; Livi, K. J.; Wang, C. Highly Dense Cu Nanowires for Low-Overpotential $\mathrm{CO}_{2}$ Reduction. Nano Lett. 2015, 15, 6829-6835.

(13) Ma, M.; Djanashvili, K.; Smith, W. A. Selective Electrochemical Reduction of $\mathrm{CO}_{2}$ to $\mathrm{CO}$ on CuO-Derived Cu Nanowires. Phys. Chem. Chem. Phys. 2015, 17, 20861-20867.

(14) Chi, D.; Yang, H.; Du, Y.; Lv, T.; Sui, G.; Wang, H.; Lu, J. Morphology-Controlled CuO Nanoparticles for Electroreduction of $\mathrm{CO}_{2}$ to Ethanol. $R S C A d v . \mathbf{2 0 1 4}, 4,37329-37332$. 
(15) Kas, R.; Kortlever, R.; Milbrat, A.; Koper, M. T. M.; Mul, G.; Baltrusaitis, J.

Electrochemical $\mathrm{CO}_{2}$ Reduction on $\mathrm{Cu}_{2} \mathrm{O}$-Derived Copper Nanoparticles: Controlling the Catalytic Selectivity of Hydrocarbons. Phys. Chem. Chem. Phys. 2014, 16, 12194-12201.

(16) Dutta, A.; Rahaman, M.; Luedi, N. C.; Mohos, M.; Broekmann, P. Morphology Matters:

Tuning the Product Distribution of $\mathrm{CO}_{2}$ Electroreduction on Oxide-Derived $\mathrm{Cu}$ Foam Catalysts. ACS Catal. 2016, 6, 3804-3814.

(17) Gupta, N.; Gattrell, M.; MacDougall, B. Calculation for the Cathode Surface Concentrations in the Electrochemical Reduction of $\mathrm{CO}_{2}$ in $\mathrm{KHCO}_{3}$ Solutions. J. Appl. Electrochem. 2006, 36, 161-172.

(18) Varela, A. S.; Kroschel, M.; Reier, T.; Strasser, P. Controlling the Selectivity of $\mathrm{CO}_{2}$ Electroreduction on Copper: The Effect of the Electrolyte Concentration and the Importance of the Local pH. Catal. Today 2016, 260, 8-13.

(19) Roberts, F. S.; Kuhl, K. P.; Nilsson, A. Electroreduction of Carbon Monoxide over a Copper Nanocube Catalyst: Surface Structure and pH Dependence on Selectivity. ChemCatChem 2016, 8, 1119-1124.

(20) Feng, X.; Jiang, K.; Fan, S.; Kanan, M. W. A Direct Grain-Boundary-Activity Correlation for CO Electroreduction on Cu Nanoparticles. ACS Cent. Sci. 2016, 2, 169-174.

(21) Verdaguer-Casadevall, A.; Li, C. W.; Johansson, T. P.; Scott, S. B.; McKeown, J. T.; Kumar, M.; Stephens, I. E. L.; Kanan, M. W.; Chorkendorff, I. Probing the Active Surface Sites for CO Reduction on Oxide-Derived Copper Electrocatalysts. J. Am. Chem. Soc. 2015, 137, 9808-9811.

(22) Tang, W.; Peterson, A. A.; Varela, A. S.; Jovanov, Z. P.; Bech, L.; Durand, W. J.; Dahl, S.; Nørskov, J. K.; Chorkendorff, I. The Importance of Surface Morphology in Controlling 
the Selectivity of Polycrystalline Copper for $\mathrm{CO}_{2}$ Electroreduction. Phys. Chem. Chem. Phys. 2012, 14, 76-81.

(23) Kim, D.; Lee, S.; Ocon, J. D.; Jeong, B.; Lee, J. K.; Lee, J. K.; Wang, H. L.; Norskøv, J. K.; Chorkendorff, I.; Lee, K.; et al. Insights into Autonomously Formed OxygenEvacuated $\mathrm{Cu}_{2} \mathrm{O}$ Electrode for the Selective Production of $\mathrm{C}_{2} \mathrm{H}_{4}$ from $\mathrm{CO}_{2}$. Phys. Chem. Chem. Phys. 2014, 17, 1-9.

(24) Lee, S.; Kim, D.; Lee, J. Electrocatalytic Production of C3-C4 Compounds by Conversion of $\mathrm{CO}_{2}$ on a Chloride-Induced Bi-Phasic $\mathrm{Cu}_{2} \mathrm{O}-\mathrm{Cu}$ Catalyst. Angew. Chemie Int. Ed. 2015, $127,14914-14918$.

(25) Mistry, H.; Varela, A. S.; Bonifacio, C. S.; Zegkinoglou, I.; Sinev, I.; Choi, Y.-W.; Kisslinger, K.; Stach, E. A.; Yang, J. C.; Strasser, P.; et al. Highly Selective PlasmaActivated Copper Catalysts for Carbon Dioxide Reduction to Ethylene. Nat. Commun. 2016, 7, 12123.

(26) Eilert, A.; Cavalca, F.; Roberts, F. S.; Osterwalder, J.; Liu, C.; Favaro, M.; Crumlin, E. J.;

Ogasawara, H.; Friebel, D.; Pettersson, L. G. M.; et al. Subsurface Oxygen in OxideDerived Copper Electrocatalysts for Carbon Dioxide Reduction. J. Phys. Chem. Lett. 2017, 8, 285-290.

(27) Liu, C.; Lourenço, M. P.; Cavalca, F.; Diaz-Morales, O.; Duarte, H. A.; Nilsson, A.; Pettersson, L. G. M. Stability and Effects of Subsurface Oxygen in Oxide-Derived Cu Catalyst for CO2 Reduction. J. Phys. Chem. C 2017.

(28) Lide, D. R. CRC Handbook of Chemistry and Physics: A Ready-Reference Book of Chemical and Physical Data; CRC Press, 2004; Vol. 89th.

(29) Egerton, R. F. Quantitative Analysis of Energy-Loss Data. In Electron Energy-Loss 
Spectroscopy in the Electron Microscope; Springer, 2011; pp 231-291.

(30) Roberts, F. S.; Kuhl, K. P.; Nilsson, A. High Selectivity for Ethylene from Carbon

Dioxide Reduction over Copper Nanocube Electrocatalysts. Angew. Chemie 2015, 127, $5268-5271$.

(31) Lynn, K. G.; MacDonald, J. R.; Boie, R. A.; Feldman, L. C.; Gabbe, J. D.; Robbins, M. F.;

Bonderup, E.; Golovchenko, J. Positron-Annihilation Momentum Profiles in Aluminum:

Core Contribution and the Independent-Particle Model. Phys. Rev. Lett. 1977, 38, 241244.

(32) Ferragut, R. Atomic Fraction around Defects Associated with Nanoparticles in AlCuMg Alloys. In Physica B: Condensed Matter; 2012; Vol. 407, pp 2676-2683.

(33) Kas, R.; Kortlever, R.; Y1lmaz, H.; Koper, M. T. M.; Mul, G. Manipulating the Hydrocarbon Selectivity of Copper Nanoparticles in $\mathrm{CO}_{2}$ Electroreduction by Process Conditions. ChemElectroChem 2015, 2, 354-358.

(34) Morrison, T. I.; Brodsky, M. B.; Zaluzec, N. J. EELS as a Probe of D-Band Occupancy in Magnetic Alloys. Ultramicroscopy 1987, 22, 125-127.

(35) Cavalca, F.; Laursen, A. B.; Wagner, J. B.; Damsgaard, C. D.; Chorkendorff, I.; Hansen, T. W. Light-Induced Reduction of Cuprous Oxide in an Environmental Transmission Electron Microscope. ChemCatChem 2013, 5, 2667-2672.

(36) Paterson, J. H.; Krivanek, O. L. Elnes of 3d Transition-Metal Oxides. Ultramicroscopy 1990, 32, 319-325.

(37) Leapman, R. D.; Grunes, L. A.; Fejes, P. L. Study of the $\mathrm{L}_{23}$ Edges in the $3 d$ Transition Metals and Their Oxides by Electron-Energy-Loss Spectroscopy with Comparisons to Theory. Phys. Rev. B 1982, 26, 614-635. 
(38) Ebert, H.; Stöhr, J.; Parkin, S. S. P.; Samant, M.; Nilsson, A. L -Edge X-Ray Absorption in Fcc and Bcc Cu Metal: Comparison of Experimental and First-Principles Theoretical Results. Phys. Rev. B 1996, 53, 16067-16073.

(39) Xin, H.; Larue, J.; Öberg, H.; Beye, M.; Dell'Angela, M.; Turner, J. J.; Gladh, J.; Ng, M.

L.; Sellberg, J. A.; Kaya, S.; et al. Strong Influence of Coadsorbate Interaction on CO Desorption Dynamics on Ru(0001) Probed by Ultrafast X-Ray Spectroscopy and Ab Initio Simulations. Phys. Rev. Lett. 2015, 114, 1-6.

(40) Föhlisch, A.; Nyberg, M.; Bennich, P.; Triguero, L.; Hasselström, J.; Karis, O.; Pettersson, L. G. M.; Nilsson, A. The Bonding of CO to Metal Surfaces. J. Chem. Phys. 2000, 112, $1946-1958$.

(41) Pettersson, L. G. M.; Nilsson, A. A Molecular Perspective on the D-Band Model: Synergy Between Experiment and Theory. Top. Catal. 2014, 57, 2-13.

(42) Nilsson, A.; Pettersson, L. G. M.; Nørskov, J. K. Chemical Bonding at Surfaces and Interfaces; Elsevier, 2008.

(43) Folegati, P.; Makkonen, I.; Ferragut, R.; Puska, M. J. Analysis of Electron-Positron Momentum Spectra of Metallic Alloys as Supported by First-Principles Calculations. Phys. Rev. B 2007, 75, 54201.

(44) Druzhkov, A. P.; Gizhevskii, B. A.; Arbuzov, V. L.; Kozlov, E. A.; Shalnov, K. V; Naumov, S. V; Perminov, D. A. Electronic and Structural Properties of Micro-and Nanometre-Sized Crystalline Copper Monoxide Ceramics Investigated by Positron Annihilation. J. Phys. Condens. Matter 2002, 14, 7981-7990.

(45) Ma, Y.; Wang, H.; Li, H.; Key, J.; Ji, S.; Wang, R. Synthesis of Ultra Fine Amorphous PtP Nanoparticles and the Effect of PtP Crystallinity on Methanol. RSC Adv. 2014, 4, 
20722-20728.

(46) Zhu, Z.; Ma, J.; Xu, L.; Xu, L.; Li, H.; Li, H. Facile Synthesis of Co-B Amorphous Alloy in Uniform Spherical Nanoparticles with Enhanced Catalytic Properties. ACS Catal. 2012, 2, 2119-2125. 
TOC graphic

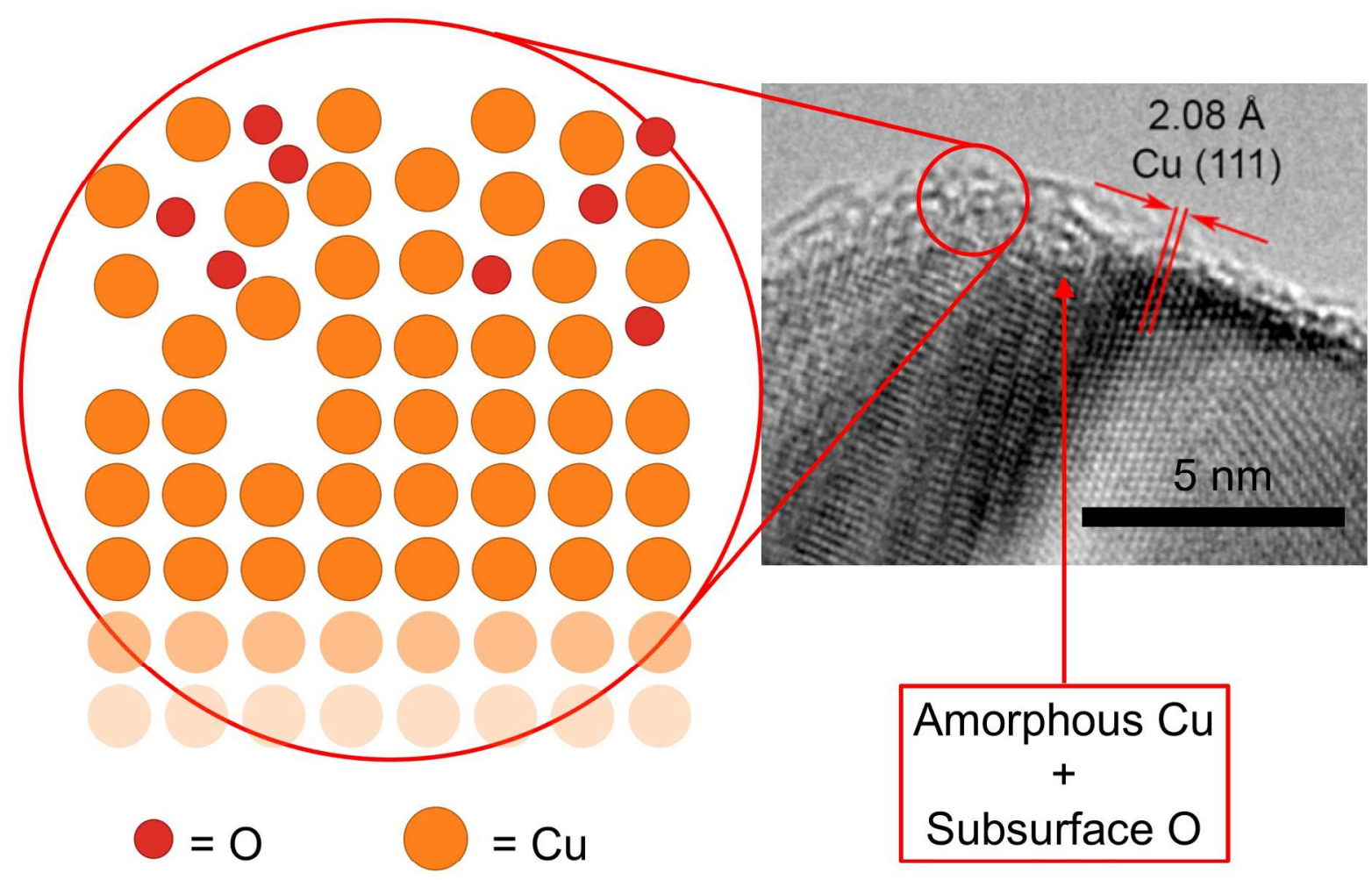

